\title{
Treatment of melanoma with selected inhibitors of signaling kinases effectively reduces proliferation and induces expression of cell cycle inhibitors
}

\author{
Dorota Ciołczyk-Wierzbicka ${ }^{1}\left[\right.$ ] Dorota Gil ${ }^{1} \cdot$ Piotr Laidler $^{1}$
}

Received: 16 November 2017 / Accepted: 30 November 2017 / Published online: 6 December 2017

(c) The Author(s) 2017. This article is an open access publication

\begin{abstract}
Cancer treatment often tends to involve direct targeting enzymes essential for the growth and proliferation of cancer cells. The aim of this study was the recognition of the possible role of selected protein kinases: PI3K, ERK1/2, and mTOR in cell proliferation and cell cycle in malignant melanoma. We investigated the role of protein kinase inhibitors: U0126 (ERK1/2), LY294002 (PI3K), rapamycin (mTOR), everolimus (mTOR), GDC-0879 (B-RAF), and CHIR-99021 (GSK3beta) in cell proliferation and expression of crucial regulatory cell cycle proteins in human melanoma cells: WM793 (VGP) and Lu1205 (metastatic). They were used either individually or in various combinations. The study on the effect of signaling kinases inhibitors on proliferation-BrdU ELISA test after 48-72 h. Their effect on the expression of cell cycle regulatory proteins: cyclin D1 and D3, cyclin-dependent kinase CDK4 and CDK6, and cell cycle inhibitors: p16, p21, and p27, was studied at the protein level (western blot). Treatment of melanoma cells with protein kinase inhibitors led to significantly decreased cell proliferation except the use of a GSK-3 $\beta$ kinase inhibitors-CHIR-99021. The significant decrease in the expression of selected cyclins and cyclin-dependent kinases (CDKs) with parallel increase in the expression of some of cyclin-dependent kinases inhibitors and in consequence meaningful reduction in melanoma cell proliferation by the combinations of inhibitors of signaling kinases clearly showed the crucial role of AKT, ERK 1/2, and mTOR signal transduction in melanoma progression. The results unanimously indicate those pathways as an important target for treatment of melanoma.
\end{abstract}

Keywords Melanoma $\cdot$ Proliferation $\cdot$ Cell cycle $\cdot$ Protein kinase inhibitors

\section{Introduction}

Treatment of melanoma causes many problems as melanoma is a heterogeneous disease, resistant to standard chemotherapy, and only subsets of patients respond to systemic therapies [1-3].

The transformation of melanocytes to melanoma cells is characterized by uncontrolled proliferation as a result of abnormalities in cell cycle regulatory mechanisms. In normal cells, the cell cycle is controlled at multiple stages related to DNA replication, cell division, and cell growth [4]. This process also includes mechanisms to ensure that

Dorota Ciołczyk-Wierzbicka

mbciolcz@cyf-kr.edu.pl

1 Chair of Medical Biochemistry, Jagiellonian University Medical College, ul. Kopernika 7, 31-034 Kraków, Poland errors are corrected, and if not, the cells commit suicide (apoptosis) [5].

In melanoma, genetic mutations leading to disturbance of these regulatory mechanisms result in uncontrolled cell proliferation $[4,6]$. The regulation of cell proliferation is essential for normal development and response to pathological processes such as cell damage and tumorigenesis. Progression through the cell cycle is controlled by cyclins, cyclin-dependent kinases, and inhibitory proteins. Cyclin D1 is usually associated with CDK4, whereas cyclin D3 preferentially partners CDK6 [7].

Cyclins, cyclin-dependent kinases, and inhibitory proteins play an important role in the regulation of cell proliferation, through the $\mathrm{G} 1$ restriction point by regulating the function of $\mathrm{pRb}$ (retinoblastoma protein) [8].

Cancerous phenotypes result from the dysregulation of more than 500 genes at multiple steps in cell signaling pathways. Most melanomas are driven by BRAF(V600E)activating mutations [9]. 
Potential synergy exists between the combination of CDK4/6 inhibitors with existing therapies targeting the MAPK pathway, particularly in subsets of metastatic melanomas such as NRAS and BRAF mutants [3, 10].

In case of V600 BRAF mutation, it seems effective to use RAF inhibitors; RAS and NF1-mutant melanomas have deregulated MEK signaling pathways that are highly sensitive to MEK kinase inhibitors [11], while overexpression of AKT3 isoforms that affects MEK and mTOR signaling pathways has been observed with: wild-type RAS NF1 and Triple Wild-Type cancers, suggesting effective use of target therapy for MEK and PI3K/AKT/mTOR signaling pathway [11].

Activation of mammalian target of rapamycin (mTOR) signaling has been demonstrated in aggressive cancers such as gastric [12] and cervical cancer [13]. The effect of mTOR signaling has also been observed in bladder cancer [14]. The expression of phospho-S6 (a marker of mTOR activity) was found in 55\% of muscle-invasive bladder cancers with evident lymph node metastases [15]. mTOR activity was demonstrated to be associated with increased pathological stage and reduced patient survival [15]. Recent research suggests that mTOR mutations often occur in melanoma patients and are of worse therapeutic prognosis [16]. Clinical trials with $\mathrm{PI} 3 \mathrm{~K} / \mathrm{AKT} / \mathrm{mTOR}$ pathway inhibitors may be beneficial for melanoma patients with specific mTOR mutations [16].

Understanding melanoma at the molecular level and identifying its novel molecular targets are needed to improve therapeutic strategies. Therefore, the purpose of this study was to recognize the effect of selected signaling kinase inhibitors on melanoma cells proliferation and the expression of cell cycle regulatory proteins.

\section{Materials and methods}

\section{Cell culture}

Human melanoma cell lines: WM793 [vertical-growth phase (VGP)]—Lu1205 (metastatic; biopsy taken from the lung; selection in mice; a culture from the primary site (sternum area) from the same donor as WM793). Cells were cultured in RPMI 1640 medium supplemented with $10 \%$ fetal bovine serum and antibiotics: penicillin and streptomycin. Cells were incubated at $37^{\circ} \mathrm{C}$ in a humidified atmosphere of $5 \% \mathrm{CO}_{2}$ in air. Cells were treated with inhibitors: (1) PI3KLY294002 (Cell Signaling TM) - $20 \mu \mathrm{M}$ concentration, (2) ERK1/2-U0126 (Cell Signaling TM) - $10 \mu \mathrm{M}$ concentration, (3) mTOR - rapamycin (Selleck) $-5 \mathrm{nM}$ concentration, (4) mTOR-everolimus (Selleck) $-5 \mathrm{nM}$ concentration, (5) B-RAF-GDC-0879 (Selleck)-2 $\mu$ M concentration, (6) GSK-3 $\beta$-CHIR-99021(Selleck) $-2 \mu$ M concentration. Cells were obtained from the ESTDAB Melanoma Cell Bank (Tubingen, Germany).

\section{Cell proliferation assay}

The proliferation of cells was assessed with the BrdU ELISA test (Roche) after 48-72 h, as described previously [17].

\section{Cytotoxicity assay}

Cytotoxicity of PI3K inhibitor-LY294002 $(20 \mu \mathrm{M})$, ERK1/2 inhibitor-U0126 $(10 \mu \mathrm{M})$, mTOR inhibitor-rapamycin and everolimus (5 nM), B-RAF-GDC-0879 $(2 \mu \mathrm{M})$ and GSK-3 $\beta$-CHIR-99021 $(2 \mu \mathrm{M})$ assay was determined using Cytotoxicity Detection Kit LDH, Roche, Germany. In all examined melanoma cell lines, inhibitors LY294002, U0126, rapamycin, everolimus, GDC-0879, and CHIR99021 showed no cytotoxicity effect tested in a culture medium at the time of $72 \mathrm{~h}$. LDH activity in the culture medium in no case exceeded $3 \%$.

\section{Western blot analysis}

Preparation of samples for electrophoresis and western blot analysis as described previously [17]. They used to analyze the following antibodies: Cyclin D1 (\#2926 Cell Signaling TM), cyclin D3 (\#2936 Cell Signaling TM), CDK4 kinase (\#2906 Cell Signaling TM), CDK6 kinase (\#3136 Cell Signaling TM), p16 (\#4824 Cell Signaling TM), p21 (\#2946 Cell Signaling TM), p27 (\#2552 Cell Signaling TM), and $\beta$-actin (A2228, SIGMA).

\section{Densitometry analysis}

Densitometry analyses of western blot analysis were performed on raw volume (sum of intensities of bound-volume calculated from the area of the peak) using SynGene Gene Tools version 4.03.0 (Synoptics Ltd Beacon House, Nuffield Road Cambridge, CB4 1TF, UK).

\section{Statistics}

Cell proliferation data were calculated from mean eight values of three times replicate experiments. All results are presented as experimental mean values which were compared using one-way ANOVA with the Tukey's post hoc test (Statistica ver. 12, StatSoft); asterisk (*) indicates a significant difference: $* p<0.05, * * p<0.005,{ }^{* * *} p<0.0005$. 


\section{Results}

\section{Cell proliferation}

The study of the role of protein kinases inhibitors on proliferation of melanoma cells was performed using the BrdU ELISA test after $48-72 \mathrm{~h}$. We did not observe cytotoxic effect of none of the tested protein kinase inhibitors. In the case of each of them used in indicated concentrations: (1) PI3K inhibitor-LY294002 $(20 \mu \mathrm{M})$, (2)
ERK1/2 inhibitor-U0126 $(10 \mu \mathrm{M})$, (3) mTOR inhibitors-rapamycin and everolimus (both $5 \mathrm{nM}$ ), (4) B-RAF inhibitor-GDC-0879 $(2 \mu \mathrm{M})$, and (5) GSK-3 $\beta$ inhibitorCHIR-99021 $(2 \mu \mathrm{M})$ either alone or in various combinations the LDH activity in the media of cells treated for $72 \mathrm{~h}$ did not exceed $3 \%$.

Metastatic melanoma cell line-Lu1205, showed larger decreases in cell proliferation than the primary one, WM793. The treatment of Lu1205 cells with individual inhibitors of mTOR either everolimus $(p<0.0005)$ or rapamycin $(p<0.0005)$ and PI3K inhibitor LY294002 $(p<0.0005)$
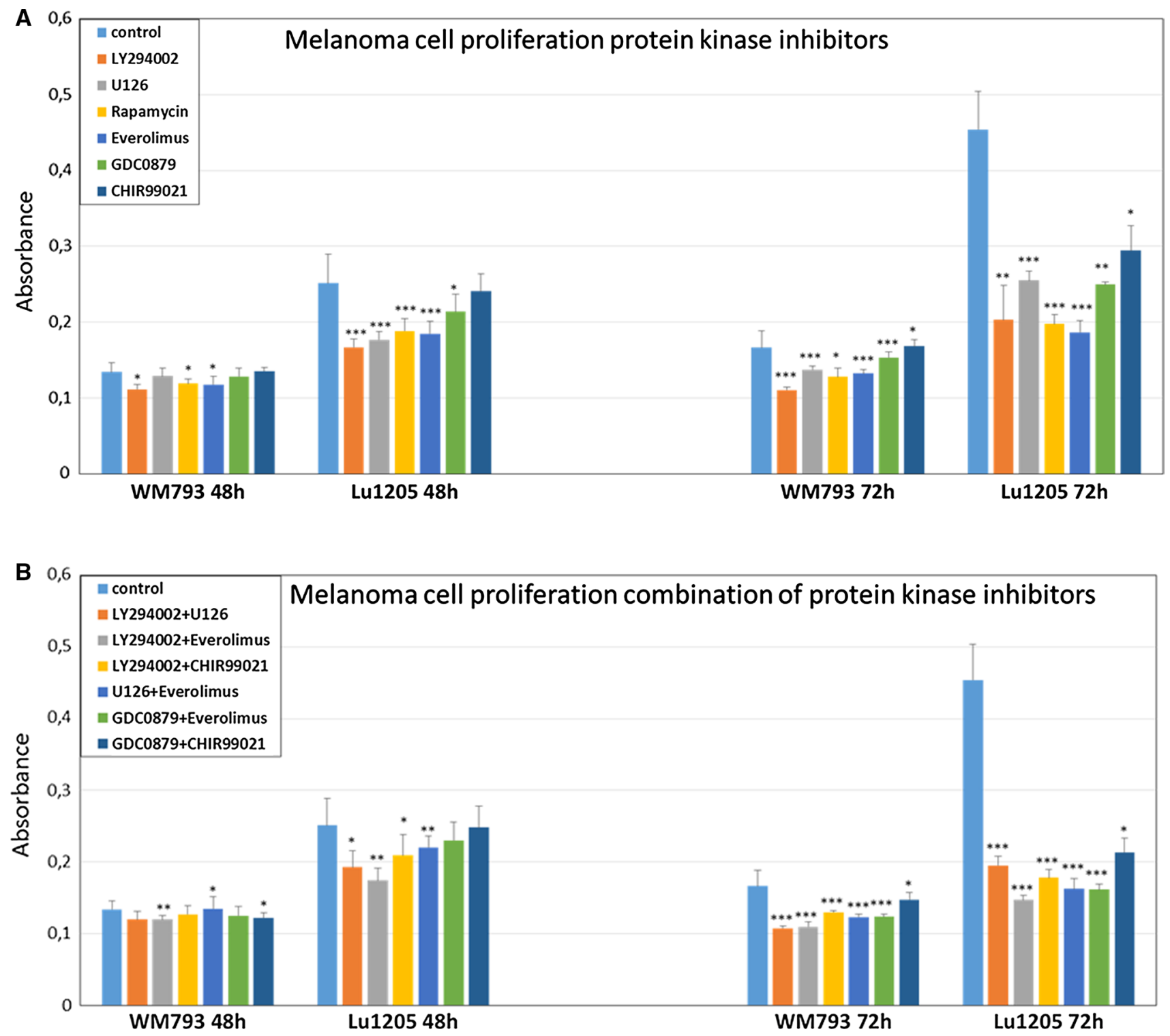

Fig. 1 Effect of protein kinase inhibitors on melanoma cell proliferation (a). The effect of combination of protein kinase inhibitors on melanoma cells proliferation (b). The proliferation of cells was assessed with the BrdU ELISA test after $48 \mathrm{~h}$ and $72 \mathrm{~h}$. Values are expressed as mean \pm standard deviation in 8 wells in three independ- ent experiments. All results are presented as experimental mean values which were compared using one-way ANOVA with the Tukey's post hoc test (Statistica ver. 12, StatSoft); asterisk (*) indicates a significant difference: ${ }^{*} p<0.05,{ }^{* *} p<0.005,{ }^{* * *} p<0.0005$ 
for $48 \mathrm{~h}$ led to the reduction in their proliferation in the range of $12-34 \%$ (Fig. 1a). The use of $n$ GSK-3 $\beta$ kinase inhibitors-CHIR-99021, did not cause any decrease in cell proliferation.

The prolongation of treatment of Lu1205 metastatic melanoma cells up to $72 \mathrm{~h}$ led in the case of all the used inhibitors to significant reduction in their proliferation, reaching about $50 \%$, for each of the three of them already mentioned above-everolimus $(p<0.0005)$, rapamycin $(p<0.0005)$, and LY294002 $(p<0.005)$. The treatment of Lu1205 cells with U0126 (ERK1/2 inhibitor) reduced proliferation about $34 \%$ ( $p<0.0005)$, whereas their treatment with B-RAF inhibitor-GDC-0879, only to about $24 \%$ $(p<0.005)$ (Fig. 1a).

The use of the combination of inhibitors U126 (ERK1/2) and GDC-0879 (B-RAF), each with the mTOR inhibitor-everolimus, resulted in more effective, nearly $60 \%$ $(p<0.0005)$ reduction in Lu1205 cells proliferation (Fig. 1b). The most profound inhibition was, however, noticed in the case of applications of the combination of mTOR inhibitor-everolimus, with PI3K kinase inhibitor-LY294002, which reduced proliferation of Lu1205 metastatic melanoma cells by $62 \%(p<0.0005)$ in (Fig. 1b).

WM793 cells from primary site (VGP) did not respond as effectively as the metastatic ones (Lu1205) to the treatment with each of the inhibitors used in the individual mode since 48-h incubation had almost no effect on their proliferation, while the prolongation of the incubation up to $72 \mathrm{~h}$ led to its $25-30 \%$ reduction in the case of everolimus $(p<0.0005)$, rapamycin ( $p<0.05)$, and LY294002 ( $p<0.0005)$ (Fig. 1a).

The use of the various combinations of the studied inhibitors resulted in higher reduction in WM793 cells proliferation, however, not as high as in the case of Lu1205 cells (Fig. 1b). Again in the case of everolimus and LY294002 $(p<0.0005)$ as well as U126 and LY294002 $(p<0.0005)$ used together, the decrease in the proliferation was the highest one, reaching nearly 36\% (Fig. 1b).

\section{Effect of protein kinases inhibitors on cell cycle regulatory proteins in melanoma cells}

We also studied the effect of using the individual inhibitors: PI3K inhibitor-LY294002, ERK1/2-U0126; mTOR: rapamycin and everolimus; B-RAF-GDC-0879 and GSK$3 \beta$-CHIR-99021; and their combination on the expression of cell cycle regulatory proteins: cyclin D1 and D3, cyclindependent kinase: CDK4, CDK6, and cell cycle inhibitors: p16, p21, and p27.

In both studied melanoma cell lines expression of cyclins D1 and D3, cyclin-dependent kinases CDK4 and CDK6 were observed (Fig. 2a, b). The level of the expression of cyclin D3 in untreated cells was much higher than the level of cyclin D1, and it was much higher for both cyclins: D1 and D3 in the case of metastatic Lu 1205 cells than in WM793 primary ones.

The level of cyclin D3 and cyclin-dependent kinase 6 (CDK6) was most decreased after the application of mTOR inhibitors: rapamycin or everolimus $(\sim 60-75 \%$ relative to the untreated cells). Similar results were obtained after application of inhibitor LY294002 ( 60-70\% reduction). CHIR-99021-GSK-3 $\beta$ inhibitor did not affect the level of kinase CDK6 and cyclin D3 (Fig. 2a, b).

In the case of the use of single protein kinase inhibitors, largest decreases in cyclin D1 and cyclin-dependent kinase 4 (CDK4) expression were observed for ERK1/2-U126 and B-RAF-GDC-0879-about 50-70\% relative to the control; a little smaller effect was observed for PI3K kinase inhibitorLY294002 - about 50\%, and for the inhibitor of GSK-3 $\beta$ kinase-CHIR-99021, the effect was not observed (Fig. 2a, b).

The expression of the cell cycle inhibitors p16, p21, and p27 in untreated (control) cells was initially low in both studied melanoma cell lines. Their level increased upon application of each of the tested protein kinases inhibitors, yet the greatest increase was observed following the use of mTOR inhibitors: rapamycin and everolimus-about $70 \%$, and B-RAF inhibitor GDC-0879-about 60\% (Fig. 2a, b).

The greatest simultaneous decline of cyclin D1, CDK4 kinase, and cyclin D3 and CDK6 kinase was observed after treatment of melanoma cell with the combination of inhibitors: mTOR - everolimus, with ERK1/2 inhibitor-U126 or B-RAF-GDC-0879 (Fig. 3a, b). The use of the combination of inhibitors everolimus and LY294002 gave noticeable effects on decrease in the level of cyclin D3 and CDK6 kinase by $60-80 \%$, while the use of the combination of inhibitors U126 and LY294002 caused a similar decline in cyclin D1 and CDK4 kinase (Fig. 3a, b).

The decline in the level of cyclins D1 and D3, and cyclindependent kinases (CDK4, CDK6) was accompanied by the increase in the level of protein: p16, p21, and p27 (Fig. 3a, b).

\section{Discussion}

In this study, we were able to show that all but one selected (tested) protein kinases inhibitors: PI3K (LY294002), ERK1/2 (U0126), mTOR (rapamycin and everolimus), B-RAF (GDC-0879), and GSK-3 $\beta$ (CHIR-99021) used individually or in combination had strong anti-proliferative effect on melanoma cell lines. In the case of treatment of melanoma cells with each of inhibitors used in individual mode, the best results were obtained for mTOR inhibitor (either everolimus or rapamycin). It is worth to notice that the significant reduction in proliferation was observed for as low as $5 \mathrm{nM}$ inhibitor's concentration which lays within the 

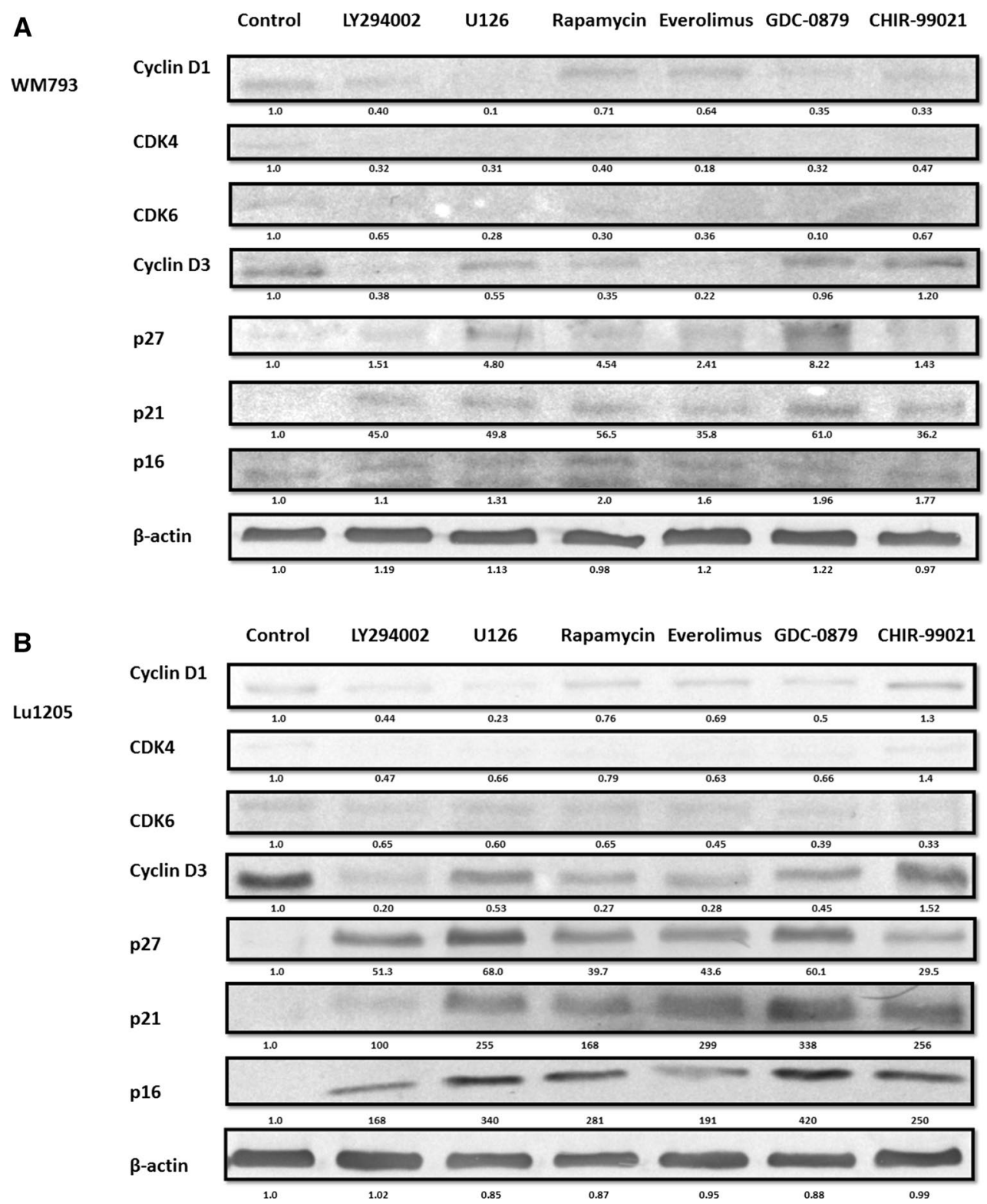

Fig. 2 Effect of protein kinase inhibitors on cell cycle protein in melanoma cells. Melanoma cell lines: a WM793, b Lu1205 were treated with protein kinase inhibitors. Cell cycle protein expression was analyzed by western blot. Densitometry analyses of western blot were performed on raw volume (sum of intensities of bound-volume calculated from the area of the peak) using SynGene Gene Tools ver- sion 4.03.0 (Synoptics Ltd Beacon House, Nuffield Road Cambridge, CB4 1TF, UK). Densitometry was used to normalize to control (melanoma cells untreated with protein kinase inhibitors). Presented are representative of at least three independent experiments with similar results range of recommended dose for treatment of human ovarian cancer (3-8 nM) [18].

A little less effective in that respect were PI3K and ERK1/2 inhibitors-LY294002 and U126, respectively.

In the case of an inhibitor of GSK-3 $\beta$ (CHIR-99021), no effect on proliferation after 48 -h treatment was found. Similar results on the use of CHIR-99021 inhibitor were reported by [19]; GSK-3 $\beta$ inhibition promotes proliferation and neuronal differentiation of human-induced pluripotent stem cell-derived neural progenitors [20]. On the other hand, induction of apoptosis in pancreatic cancer cells was observed after application of GSK-3 $\beta$ (CHIR-99021) kinase inhibitor [21].

We therefore sought to see if inhibition of that important kinase might have any effect in the case of melanoma cells.

Application of the combination of protein kinase inhibitors gave better results than the use of inhibitors individually. The best results were obtained while using a combination 


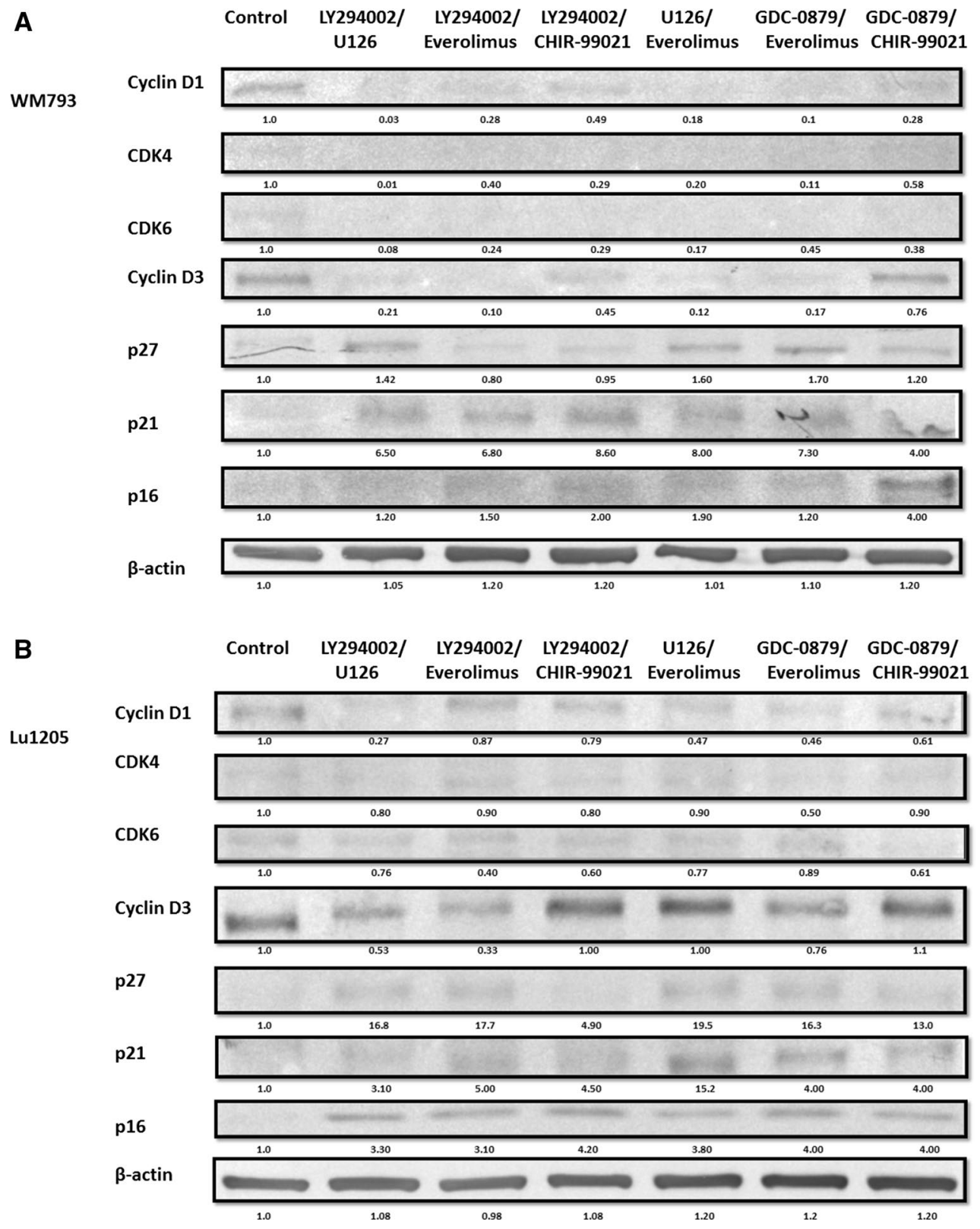

Fig. 3 Effect of combination of protein kinase inhibitors on cell cycle protein in melanoma cells. Melanoma cell lines: a WM793, b Lu1205 were treated with combination of protein kinase inhibitors. Cell cycle protein expression was analyzed by western blot. Densitometry analyses of western blot were performed on raw volume (sum of intensities of bound-volume calculated from the area of the peak) using

of everolimus and LY294002. Similar results were also obtained for the combination of everolimus and U126 or GDC-0879.

The use of signaling kinases inhibitors were also shown to effect the expression of proteins that are involved in the regulation of the cell cycle which justifies their influence on melanoma cells proliferation. Treatment of melanoma cells with inhibitor of ERK1/2 kinase-U126 and
SynGene Gene Tools version 4.03.0 (Synoptics Ltd Beacon House, Nuffield Road Cambridge, CB4 1TF, UK). Densitometry was used to normalize to control (melanoma cells untreated with protein kinase inhibitors). Presented are representative of at least three independent experiments with similar results

B-RAF-GDC-0879, resulted in the most profound reduction in expression of cyclin D1 and CDK4 kinase but only slightly affected the level of cyclin D3 and CDK6 kinase. The use of mTOR inhibitors everolimus or rapamycin led to the opposite effect and resulted in a significant decrease in the level of cyclin D3 and CDK6 kinase while to only moderate decrease in cyclin D1 and CDK4 kinase levels. 
Those observations remain in concert with recently reported results of preclinical studies carried out by a number of centers with the use of ERK1/2 inhibitors which confirm that the decrease in the forms of phosphorylated ERKpERK is accompanied by the decrease in the expression of cyclin D1 $[22,23]$. The role of cyclin D1 in melanoma cells is, however, controversial. In many studies, expression of cyclin D1 is enhanced in primary and metastatic melanoma [7, 24]. On contrary, some histopathological data do not show a statistically significant difference in the level of this cyclin [25], and others suggest that cyclin D1 expression significantly increases due to tumor progression yet decreases in metastases [26]. Some authors suggest that expression of cyclin D1 is the effect of upregulation by constitutive B-RAF-MEK-ERK1/2 signaling initiated by mutant B-RAF [7, 26, 27]. Such relation between hyperactive signaling pathway and cyclin D1 expression may explain its relatively low sensitivity to PI3K and mTOR inhibitors treatment.

According to the literature, the level of cyclin D3 is significantly higher in melanoma than in dysplastic nevi. It can therefore be used as a diagnostic marker for differentiation of these lesions in histologically doubtful cases [8]. Flørenes et al. [28] have shown that expression of cyclin D3 is an important factor in predicting the clinical outcome for patients with superficial spreading melanoma, whereas the level of cyclin D1 expression has no impact on tumor progression. The expression of cyclin D3 in melanoma cells is associated with regulation of the cell cycle at the G1-S phase, which is necessary for efficient entry into $S$ phase, increased cell proliferation, and is a poor prognostic factor [7, 8, 28]. The data obtained by Spofford et al. [7] suggest that the activity of cyclin D3 is regulated by fibronectinmediated PI3K signaling but not ERK1/2 one, which may explain relatively small decrease in the level of cyclin D3 after the application of U126.

The use of protein kinase inhibitors decreased the level of cyclin D1 and D3 and the cyclin-dependent kinase CDK4 and CDK6, which was accompanied by increased expression of cell cycle inhibitors p16, p21, and p27.

The highest increase in $\mathrm{p} 16$ suppressor protein was observed using U126-ERK1/2 inhibitor and rapamycin or everolimus-mTOR inhibitors, a significant increase was also observed after application B-RAF inhibitor-GDC-0879.

Monahan et al. [29] observed potent cooperation between the loss of somatic p16 and acceleration of melanoma genesis, a finding consistent with the view of more prominent tumor suppressor role of p16 relative to p53 in human melanoma. Loss of p16-Rb and ARF-p53 tumor suppressor pathways, as well as activation of RAS-RAF signaling, is seen in a majority of human melanomas [29].

Use of the combination of inhibitors of signaling kinases led to a greater decrease in the level of cyclin
D1 and D3 and the cyclin-dependent kinase CDK4 and CDK6 than the application of inhibitors in single mode. The largest decreases in the level of both cyclin D1 and D3 and proteins CDK4 and CDK6 were observed after treatment with the following combination of inhibitors: everolimus and B-RAF inhibitor GDC-0879 or everolimus with ERK1/2 inhibitor U126. Simultaneous application of inhibitor everolimus and that of PI3K-LY29004 gave limited decrease in expression of cyclin D1 and CDK4 kinase but significantly decreased the level of cyclin D3 and CDK6 kinase. However, using a combination of inhibitors of PI3K-LY29004 and ERK1/2-U126 resulted in decreased expression of cyclin D1 and CDK4 and slight decrease in the level of cyclin D3 and CDK6 kinase. The decline in the level of cyclin is accompanied by an increase in the level of tumor suppressor proteins p16, p21, and p27. The highest increase tumor suppressor protein was observed in combinations: mTOR inhibitor-everolimus and ERK1/2U126, slightly lower for the everolimus and GDC-0879.

Everolimus is a new hope for patients with breast cancer [30]. mTOR inhibitor everolimus (RAD001), an orally administered drug, was recently approved by the US-FDA in combination with exemestane (aromatase inhibitors) for treatment of "hormone receptor-positive" (HR-positive) metastatic breast cancer [31,32]. Study conducted by a group of Lui et al. [33] demonstrated that everolimus inhibits the proliferation of aromatase inhibitor-resistant breast cancer cells through the downregulation of estrogen receptor expression. Another study [15] showed that everolimus exerts anticancer activity in bladder cancer cells and proposes its role in effective disturbing the growth of bladder cancer cells and T cell lymphoma [34]. Research carried out of animal models have demonstrated that agents targeting mTOR pathway can lead to significant inhibition of proliferation, differentiation, and tumor progression in specific pancreatic ductal adenocarcinoma subpopulations [35].

The presented study is up to our knowledge the only such extensive an promising attempt to recognize and determine which inhibitors of most important signaling kinases as well as their combinations could be in future effectively used in treatment of various subtypes of cutaneous melanoma.

Acknowledgements This work was supported by a Grant from Ministry of Science and Higher Education through Jagiellonian University Medical College, Krakow, Poland-K/ZDS/006458.

\section{Compliance with ethical standards}

Conflict of interest The authors declare that they have no conflict of interest. 
Human and animal rights This article does not contain any studies with human participants or animals performed by any of the authors.

Open Access This article is distributed under the terms of the Creative Commons Attribution 4.0 International License (http://creativecommons.org/licenses/by/4.0/), which permits unrestricted use, distribution, and reproduction in any medium, provided you give appropriate credit to the original author(s) and the source, provide a link to the Creative Commons license, and indicate if changes were made.

\section{References}

1. Aziz SA, Davies M, Pick E, Zito C, Jilaveanu L, Camp RL, Rimm DL, Kluger Y, Kluger HM. Phosphatidylinositol-3-kinase as a therapeutic target in melanoma. Clin Cancer Res. 2009;15(9):3029-36. https://doi.org/10.1158/1078-0432.

2. Schadendorf D, Fisher DE, Garbe C, Gershenwald JE, Grob JJ, Halpern A, Herlyn M, Marchetti MA, McArthur G, Ribas A, Roesch A, Hauschild A. Melanoma. Nat Rev Dis Prim. 2015;1:1-20. https://doi.org/10.1038/nrdp.2015.3.

3. Fedorenko IV, Gibney GT, Sondak VK, Smalley KSM. Beyond BRAF: where next for melanoma therapy? Br J Cancer. 2015;112:217-26.

4. Bertoli C, Skotheim JM, Bruin R. Control of cell cycle transcription during G1 and S phases. Nat Rev Mol Cell Biol. 2013;14(8):518-28.

5. Rastogi N, Mishra DP. Therapeutic targeting of cancer cell cycle using proteasome inhibitors. Cell Div. 2012. https://doi. org/10.1186/1747-1028-7-26.

6. Ross AL, Sanchez MI, Grichnik JM. Molecular nevogenesis. Dermatol Res Pract. 2011; https://doi.org/10.5402/2011/642157 (Article ID 463184).

7. Spofford LS, Abel EV, Boisvert-Adamo K, Aplin AE. Cyclin D3 expression in melanoma cells is regulated by adhesion-dependent phosphatidylinositol 3-kinase signaling and contributes to G1-S progression. J Biol Chem. 2006;281:25644-51.

8. Alekseenko A, Wojas-Pelc A, Lis GJ, Furgał-Borzych A, Surówka G, Litwin JA. Cyclin D1 and D3 expression in melanocytic skin lesions. Arch Dermatol Res. 2010;302(7):545-50.

9. Taylor LA, O'Day C, Dentchev T, Hood K, Chu EY, Ridky TW, Seykora JT. p15 Expression differentiates nevus from melanoma. Am J Pathol. 2016;186(12):3094-9.

10. $\mathrm{Xu} \mathrm{W}, \mathrm{McArthur} \mathrm{G}$. Cell cycle regulation and melanoma. Curr Oncol Rep. 2016. https://doi.org/10.1007/s11912-016-0524-y.

11. Ascierto PA, Atkins M, Bifulco C, Botti G, Cochran A, Davies M, Demaria S, Dummer R, Ferrone S, Formenti S, Gajewski TF, Garbe C, Khleif S, Kiessling R, Lo R, Lorigan P, Mc Arthur G, Masucci G, Melero I, Mihm M, Palmieri G, Parmiani G, Puzanov I, Romero P, Schilling B, Seliger B, Stroncek D, Taube J, Tomei S, Zarour HM, Testori A, Wang E, Galon J, Ciliberto G, Mozzillo N, Marincola FM, Thurin M. Future perspectives in melanoma research: meeting report from the "Melanoma Bridge": Napoli, December 3rd-6th 2014. J Transl Med. 2015;13:374. https://doi.org/10.1186/s12967-015-0736-1.

12. Cao GD, Xu XY, Zhang JW, Chen B, Xiong MM. Phosphorylated mammalian target of rapamycin p-mTOR is a favorable prognostic factor than mTOR in gastric cancer. PLoS ONE. 2016. https://doi.org/10.1371/journal.pone.0168085.

13. Bahrami A, Hasanzadeh M, Hassanian SM, ShahidSales S, Ghayour-Mobarhan M, Ferns GA, Avan A. The potential value of the PI3K/Akt/mTOR signaling pathway for assessing prognosis in cervical cancer and as a target for therapy. J Cell Biochem. 2017;118(12):4163-9.
14. Pinto-Leite R, Arantes-Rodrigues R, Sousa N, Oliveira PA, Santos L. mTOR inhibitors in urinary bladder cancer. Tumour Biol. 2016;37(9):11541-51.

15. Lin JF, Lin YC, Yang SC, Tsai TF, Chen HE, Chou KY, Hwang TI. Autophagy inhibition enhances RAD001-induced cytotoxicity in human bladder cancer cells. Drug Des Dev Ther. 2016;10:1501-13. https://doi.org/10.2147/DDDT.S95900.

16. Kong Y, Si L, Li Y, Wu X, Xu X, Dai J, Tang H, Ma M, Chi $\mathrm{Z}$, Sheng X, Cui C, Guo J. Analysis of mTOR gene aberrations in melanoma patients and evaluation of their sensitivity to PI3K-AKT-mTOR pathway inhibitors. Clin Cancer Res. 2016;22(4):1018-27. https://doi.org/10.1158/1078-0432. CCR-15-1110.

17. Ciołczyk-Wierzbicka D, Gil D, Laidler P. The inhibition of cell proliferation using silencing of $\mathrm{N}$-cadherin gene by siRNA process in human melanoma cell lines. Curr Med Chem. 2012;19(1):145-51.

18. Guo H, Zhong Y, Jackson AL, Clark LH, Kilgore J, Zhang L, Han J, Sheng X, Gilliam TP, Gehrig PA, Zhou C, Bae-Jump VL. Everolimus exhibits anti-tumorigenic activity in obesity-induced ovarian cancer. Oncotarget. 2016. https://doi.org/10.18632/ oncotarget.7934.

19. Esfandiari F, Fathi A, Gourabi H, Kiani S, Nemati S, Baharvand H. Glycogen synthase kinase-3 inhibition promotes proliferation and neuronal differentiation of human-induced pluripotent stem cell-derived neural progenitors. Stem Cells Dev. 2012. https://doi. org/10.1089/scd.2011.0678.

20. Pachenari N, Kiani S, Javan M. Inhibition of glycogen synthase kinase 3 increased subventricular zone stem cells proliferation. Biomed Pharmacother. 2017;93:1074-82.

21. Marchand B, Arsenault D, Raymond-Fleury A, Boisvert FM, Boucher MJ. Glycogen synthase kinase-3 (GSK3) inhibition induces prosurvival autophagic signals in human pancreatic cancer cells. J Biol Chem. 2015;290(9):5592-605. https://doi. org/10.1074/jbc.M114.616714.

22. Ambrosini G, Khanin R, Carvajal RD, Schwartz GK. Overexpression of DDX43 mediates MEK inhibitor resistance through RAS upregulation in uveal melanoma. Mol Cancer Ther. 2014;13(8):2073-80. https://doi.org/10.1158/1535-7163. MCT-14-0095.

23. Muñoz-Couselo E, García JS, Pérez-García JM, Cebrián VO, Castán JC. Recent advances in the treatment of melanoma with BRAF and MEK inhibitors. Ann Transl Med. 2015. https://doi. org/10.3978/j.issn.2305-5839.2015.05.13.

24. Ramirez JA, Diaz LK, Guitart J. Cyclin D1 expression in melanocytic lesions of the skin. Ann Diagn Pathol. 2005;9(4):185-8.

25. George E, Polissar NL, Wick M. Immunohistochemical evaluation of p16INK4A, E-cadherin, and cyclin D1 expression in melanoma and spitz tumors. Am J Clin Pathol. 2010;133(3):370-9.

26. Oba J, Nakahara T, Abe T, Hagihara A, Moroi Y, Furue M. Expression of c-Kit, p-ERK and cyclin D1 in malignant melanoma: an immunohistochemical study and analysis of prognostic value. J Dermatol Sci. 2011;62(2):116-23.

27. Bhatt KV, Hu R, Spofford LS, Aplin AE. Mutant B-RAF signaling and cyclin D1 regulate Cks1/S-phase kinase-associated protein 2-mediated degradation of p27Kip1 in human melanoma cells. Oncogene. 2007;26:1056-66.

28. Flørenes VA, Faye RS, Maelandsmo GM, Nesland JM, Holm R. Levels of cyclin D1 and D3 in malignant melanoma: deregulated cyclin D3 expression is associated with poor clinical outcome in superficial melanoma. Clin Cancer Res. 2000;6(9):3614-20.

29. Monahan KB, Rozenberg GI, Krishnamurthy J, Johnson SM, Liu W, Bradford MK, Horner J, Depinho RA, Sharpless NE. Somatic p16 (INK4a) loss accelerates melanomagenesis. Oncogene. 2010;29:5809-17. 
30. Sendur MA, Zengin N, Aksoy S, Altundag K. Everolimus: a new hope for patients with breast cancer. Curr Med Res Opin. 2014;30(1):75-87.

31. Hurvitz SA, Kalous O, Conklin D, Desai AJ, Dering J, Anderson L, O’Brien NA, Kolarova T, Finn RS, Linnartz R, Chen D, Slamon DJ. In vitro activity of the mTOR inhibitor everolimus, in a large panel of breast cancer cell lines and analysis for predictors of response. Breast Cancer Res Treat. 2015;149(3):669-80.

32. Steelman LS, Martelli AM, Cocco L, Libra M, Nicoletti F, Abrams SL, McCubrey JA. The therapeutic potential of mTOR inhibitors in breast cancer. Br J Clin Pharmacol. 2016;82(5):1189-212.

33. Lui A, New J, Ogony J, Thomas S, Lewis-Wambi J. Everolimus downregulates estrogen receptor and induces autophagy in aromatase inhibitor-resistant breast cancer cells. BMC Cancer. 2016. https://doi.org/10.1186/s12885-016-2490-z.

34. Witzig TE, Reeder C, Han JJ, LaPlant B, Mary-Stenson M, Tun HW, Macon W, Ansell SM, Habermann TM, Inwards DJ, Micallef IN, Johnston PB, Porrata LF, Colgan JP, Markovic S, Nowakowski GS, Gupta M. The mTORC1 inhibitor everolimus has antitumor activity in vitro and produces tumor responses in patients with relapsed T-cell lymphoma. Blood. 2015;126:328-35.

35. Iriana S, Ahmed S, Gong J, Annamalai AA, Richard Tuli R, Hendifar AE. Targeting mTOR in pancreatic ductal adenocarcinoma. Front Oncol. 2016. https://doi.org/10.3389/fonc.2016.00099. 